\title{
Size Reduction and Performance Enhancement of Pi Shaped Patch Antenna using Superstrate Configuration
}

\author{
Pir Saadullah Shah ${ }^{1}$, Shahryar Shafique Qureshi ${ }^{2}$, Muhammad Haneef $^{3}$, Sohail Imran Saeed ${ }^{4}$ \\ Electrical Engineering Department, Iqra National University, Peshawar, Pakistan ${ }^{1,2,4}$ \\ Electrical Engineering Department, Foundation University Islamabad, Islamabad, Pakistan ${ }^{3}$
}

\begin{abstract}
Patch antennas are modern elements of today's world communication technology. They appear to have unique characteristics and features with their unique power with handling capabilities and lighted structure. This paper focuses on superstrate configuration of patch antenna with defected ground plane and Pi Slotted radiating patch. The three different cases were taken in terms of wavelength distance to observe the performance characteristics of patch structure. The antenna designed in this study can be used for $\mathrm{S}$ and $\mathrm{C}$ band applications.
\end{abstract}

Keywords-Radiating patch; ground plane; slotted; bandwidth; gain; directivity

\section{INTRODUCTION}

Modern technology has seen a rapid growth in communication technology sector. Since from beginning of wireless communication the wireless spectrum technology has spread worldwide. Antenna technology has always been taken as keen interest by engineers and researchers of industry. Parabolic reflectors, dipole, monopole antennas almost in every field antenna technology has seen marvelous growth in communication sector. IEEE protocols have set almost bands for every communication of application purposes. ISM band deals with wearable antenna characteristics and with on its boundary S band connected which deals with GSM Wimax and Wireless technologies also serving Wi-Fi and space suit communication for astronauts and deep space missions [1-3].

This research presents a novel research of antenna on its size reduction. Patch antenna have been a prominent research figure in antennas researchers due to its unique capabilities. Patch antennas are low profile antennas that have power handling capabilities. When assembled together to form an array, these small elements can be boosted in terms of performance parameters and have also been used for deep space missions although too little spacing among these elements can give rise to coupling issue that's interaction of their magnetic fields which is improved through proper isolation techniques [4-6]. Patch antenna size can be reduced through number of techniques like Artificial Magnetic Conductors [7-8] use of Electromagnetic Band Gap Structures, EBGs [9-10] and Meta materials. However designing such antennas is little tough as they give relatively low performance parameter results and also miniaturization is not extended to big extent. Meta materials show goof approach but as they are designed individually they are extremely rare and cost of making them can differ up to great extent [11-12]. Slots can be made on the ground plane and radiating patch and have no design mechanisms and have been reported well to perform in some cases [13-15]. As some times antenna radiation and performance parameters may get distorted, they can be changed to satisfactory levels by stack and superstrate configuration [16-17].

In this research an antenna size is reduced through introduction of slots in its radiating patch and its full ground plane. After miniaturization, antenna main performance parameter which is reflection co efficient, is improved with help of Superstrate configuration alongside its other performance parameters. The superstrate configuration consists of a radiating patch faced parallel to another patch also known as parasitic patch. These patches are coupled magnetically and then are enhanced in terms of their performance characteristics.

The paper is organized as follow. Introduction comes first then Antenna design. Results and discussions covers all the performance parameters and their analysis and in the last comes Conclusion and future work

\section{ANTENNA DESIGN}

The resonance frequency for any mn of a rectangular MSA, is given by as:

$f_{0}=\frac{c}{2 \sqrt{\varepsilon_{e d c}}}\left[\left(\frac{m}{L}\right)^{2}+\left(\frac{n}{W}\right)^{2}\right]^{\frac{1}{2}}$

The $\mathrm{m}$ and $\mathrm{n}$ are modes along $\mathrm{L}$ and $\mathrm{W}$. For efficient radiation of patch, the width $\mathrm{W}$ is given by:

$\mathrm{W}=\frac{c}{2 f_{0} \sqrt{\frac{\varepsilon_{r}+1}{2}}}$

The antenna permittivity plays an important role in its design and also in performance parameter terms. Substrate thickness also has keen role in antenna design as thick substrate confines field in it.

Antenna with higher permittivity substrate always has low gain but bandwidth is better and antenna with lower permittivity substrate and with higher thickness has good gain results but bandwidth is less. In our design FR4 substrate is taken with relative permittivity of 4.4 . The basic design of patch antenna is shown in Fig. 1 with co axial cable feed. 


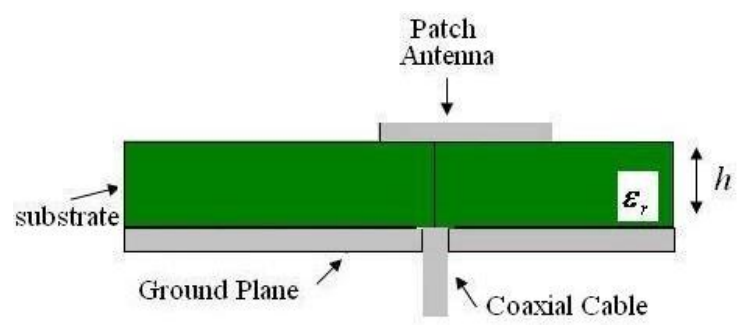

Fig. 1. Patch Antenna Layout.

As discussed earlier this research focuses on miniaturization and performance characteristics enhancement using superstrate configuration, the basic layout of superstarte configuration is shown in Fig. 2.

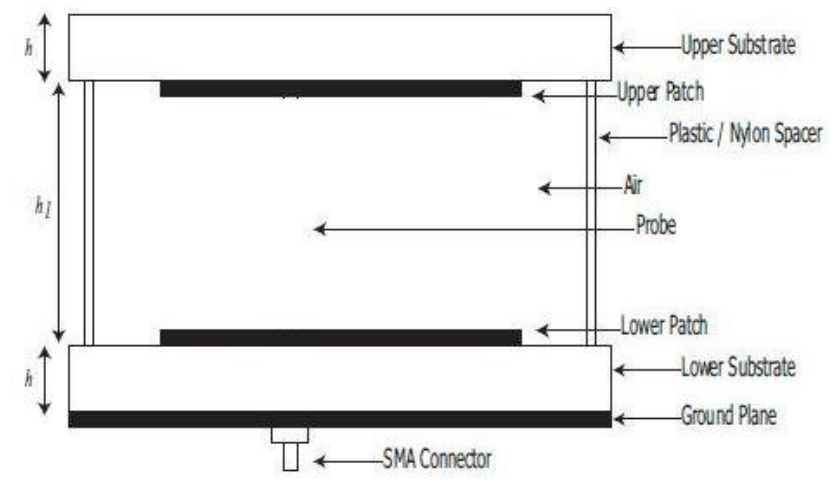

Fig. 2. Superstare Configurated Patch Antenna.

The patch antenna of $4.5 \mathrm{GHz}$ was designed and was introduced to slots and ground irregularities in both radiating patch and ground plane. The patch dimensions with help of equations mentioned in [18] were taken to be $20 \mathrm{~mm}$ width and $15 \mathrm{~mm}$ in length. The ground plane is twice the size of the calculated patch.

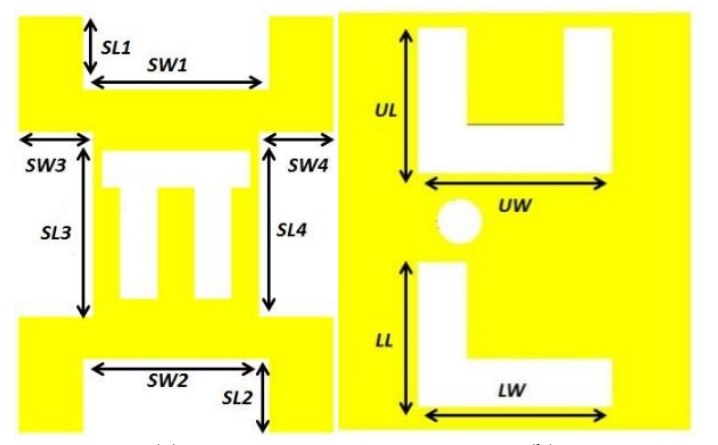

(a)

(b)

Fig. 3. Proposed Antenna (a) Radiating Patch (b) Ground Plane.

On the radiating patch, the fractional shape is made and length of $\mathrm{SL}_{1}$ and $\mathrm{SL}_{2}$ are taken to be $12 \mathrm{~mm}$ and $\mathrm{SW}_{1}$ and $\mathrm{SW}_{2}$ are taken to be $5 \mathrm{~mm}$. $\mathrm{SL}_{3}$ and $\mathrm{SL}_{4}$ are taken to be $5 \mathrm{~mm}$ and $\mathrm{SW}_{3}$ and $\mathrm{SW}_{4}$ are taken to be $12 \mathrm{~mm}$. The Pi slot is made with lengths of $5 \mathrm{~mm}$ and thickness of $2 \mathrm{~mm}$ each side. On the ground plane, the $\mathrm{U}$ and $\mathrm{L}$ slots are made the length and width of the both slots are taken to be $10 \mathrm{~mm}$ and width of each and $4 \mathrm{~mm}$ wide. The proposed geometry can be seen in Fig. 3(a) and (b) which represents patch and ground plane respectively. Through the slots, $72 \%$ miniaturization is achieved as proposed antenna current patterns are altered through slots which resulted in size reduction and multiband response.

These results are further then enhanced by implementing superstarte configuration through distance of 12, 24 and 36mm apart. The basic distance is taken to be $12 \mathrm{~mm}$ distance which represents half wavelength distance.

\section{RESULTS AND DISCUSSIONS}

The reflection co efficient parameters are shown in Fig. 4. The part (a) shows the basic graph in which antenna is clearly seen to be operating at $4.5 \mathrm{GHz}$. The antenna after miniaturization showed multiband response and when it was introduced to superstrate configuration, the proposed antenna results were enhanced and s parameter response from tri band was changed to quad band.

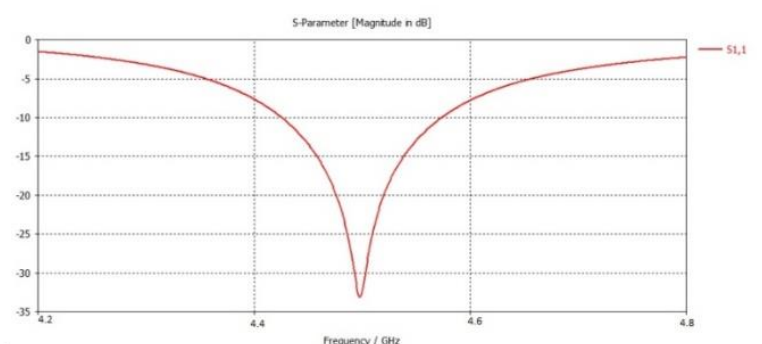

(a)

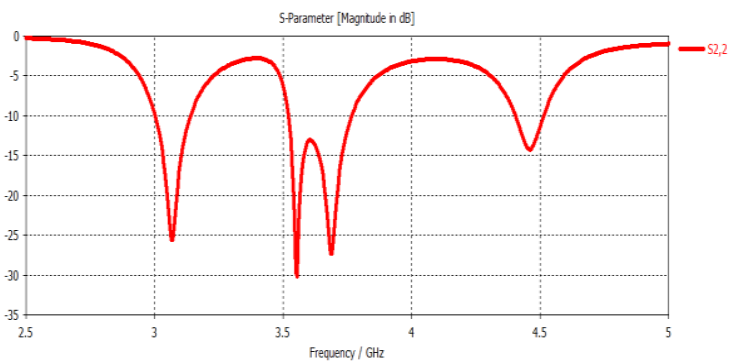

(b)

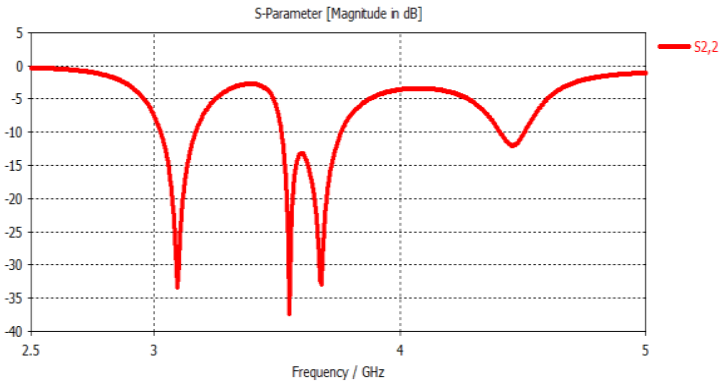

(c)

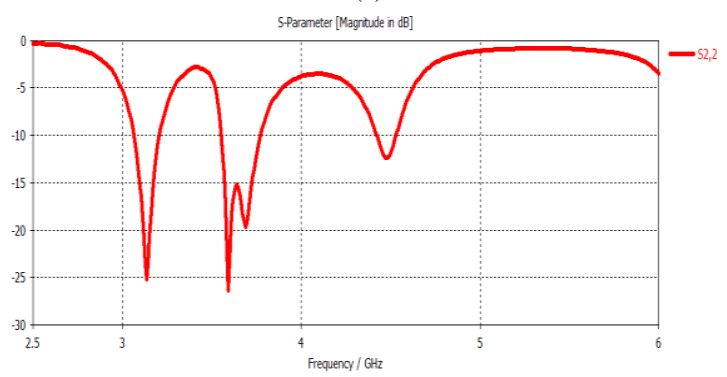

(d)

Fig. 4. Proposed Antenna S Parameters(a) Conventional Patch (b) $12 \mathrm{~mm}$ Apart (c) 24mm Apart (d) $36 \mathrm{~mm}$ Aprt. 
It can be seen that the basic $\mathrm{S}$ parameters were boosted at $24 \mathrm{~mm}$ apart distance which summed up to be clearly one wavelength distance between radiating and parasitic patch. The $\mathrm{S}$ parameters were enhanced down to $-10 \mathrm{db}$ further and bandwidth of the proposed antenna was also increased. The max gain over frequency is shown in Fig. 5.

It can be clearly seen that as duplicated in part (a) the max gain of the miniaturized patch showed low gain outputs as compared to superstrate composed gain output results. For the sake of simplicity, the gain of $24 \mathrm{~mm}$ is shown as it offered highest enhanced results.

Fig. 6 and Fig. 7 show 3 dimensional gain and 1 Dimensional polar plots of case 2 which is $24 \mathrm{~mm}$ apart configuration. From the patterns it can be seen that the proposed antenna is operating at nearly all directions in quad band response.

The detailed analysis of superstrate configuration is mentioned in Tables I to III. From the table it can clearly be seen that $24 \mathrm{~mm}$ apart distance showed better results. In all the cases the proposed antenna is well matched and is delivering maximum power as accordingly to maximum power transfer power theorem. Table IV shows the size reduction comparison at resonating frequencies.

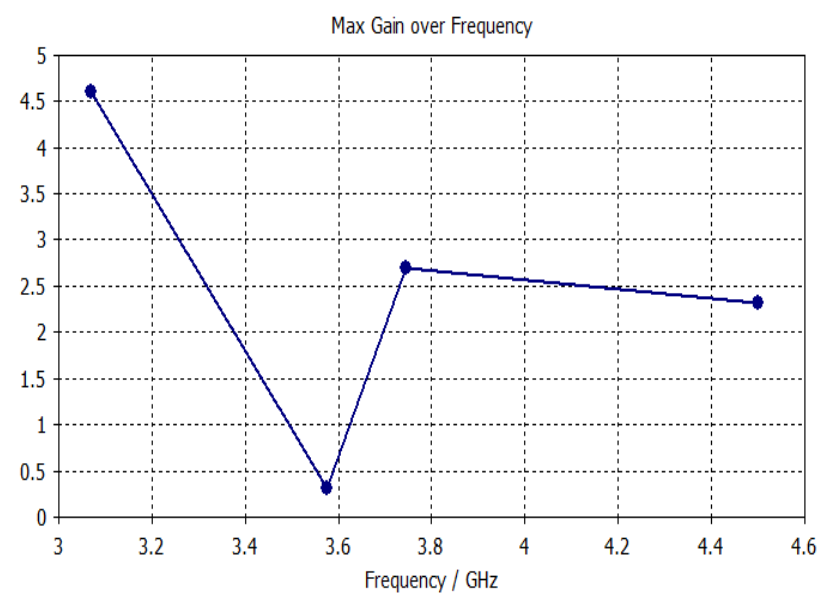

(a)

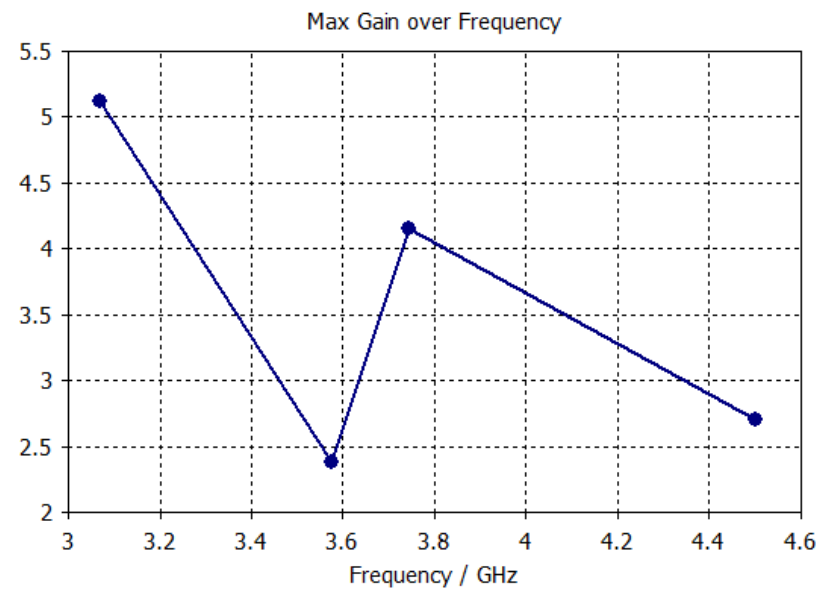

(b)

Fig. 5. Max Gain Over Frequency(a) Minituraized Patch (b) Miniaturaized Patch with Superstrate Configuration.

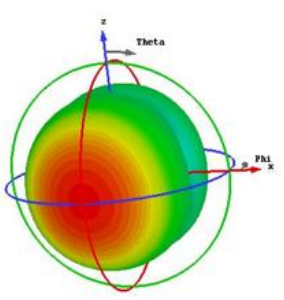

(a)

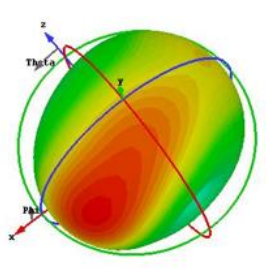

(c)
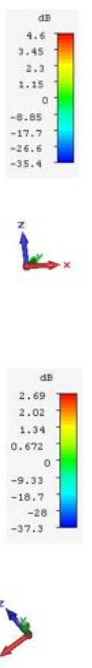

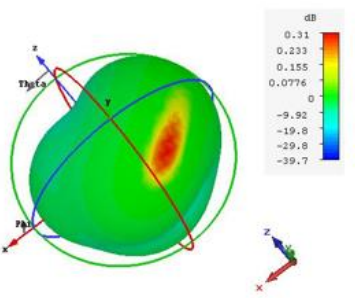

(b)

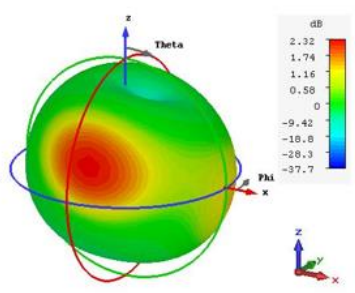

(d)

Fig. 6. Gain 3D Radiation Patterns. (a) $3.06 \mathrm{GHz}$ (b) $3.60 \mathrm{GHz}$ (c) $3.70 \mathrm{GHz}$ (d) $4.5 \mathrm{GHz}$.

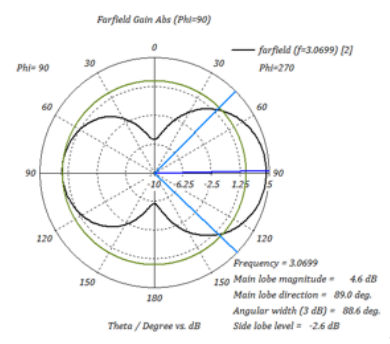

(a)

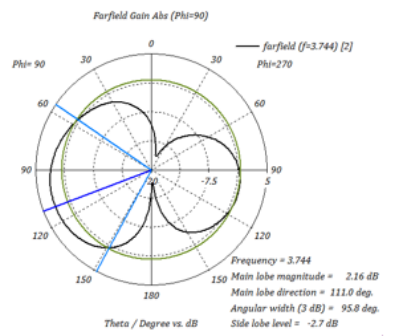

(c)

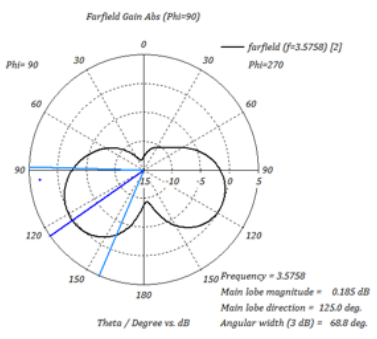

(b)

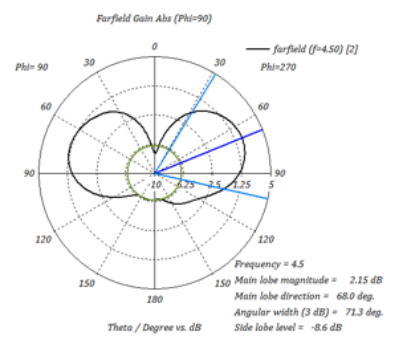

(d)

Fig. 7. Gain 1D Radiation Patterns. (a) $3.06 \mathrm{GHz}$ (b) $3.60 \mathrm{GHz}$ (c) $3.70 \mathrm{GHz}$ (d) $4.5 \mathrm{GHz}$.

TABLE I. Performance Characteistics of CASE 1

\begin{tabular}{|l|l|l|l|l|}
\hline $\begin{array}{l}\text { Antenna } \\
\text { Parameter }\end{array}$ & $\begin{array}{l}\text { Simulated } \\
\text { Value }\end{array}$ & $\begin{array}{l}\text { Simulated } \\
\text { Value }\end{array}$ & $\begin{array}{l}\text { Simulated } \\
\text { Value }\end{array}$ & $\begin{array}{l}\text { Simulated } \\
\text { Value }\end{array}$ \\
\hline $\begin{array}{l}\text { Resonant } \\
\text { Frequency }\end{array}$ & $3.06 \mathrm{GHz}$ & $3.60 \mathrm{GHz}$ & $3.7 \mathrm{GHz}$ & $4.5 \mathrm{GHz}$ \\
\hline $\begin{array}{l}\text { Return Loss } \\
\text { (S11) }\end{array}$ & $-14.33 \mathrm{~dB}$ & $-15 \mathrm{~dB}$ & $-15.3 \mathrm{~dB}$ & $-13.88 \mathrm{~dB}$ \\
\hline VSWR & 1.12 & 1.22 & 1.25 & 1.30 \\
\hline Gain & $4.12 \mathrm{~dB}$ & $2.12 \mathrm{~dB}$ & $2.39 \mathrm{~dB}$ & $2.39 \mathrm{~dB}$ \\
\hline Directivity & $6.46 \mathrm{dBi}$ & $4.3 \mathrm{dBi}$ & $3.3 \mathrm{dBi}$ & $3.2 \mathrm{dBi}$ \\
\hline Bandwidth & $110 \mathrm{MHz}$ & $60 \mathrm{MHz}$ & $175 \mathrm{MHz}$ & $103 \mathrm{MHz}$ \\
\hline
\end{tabular}


TABLE II. PERformance CHARACTEISTICS OF CASE 2

\begin{tabular}{|l|l|l|l|l|}
\hline $\begin{array}{l}\text { Antenna } \\
\text { Parameter }\end{array}$ & $\begin{array}{l}\text { Simulated } \\
\text { Value }\end{array}$ & $\begin{array}{l}\text { Simulated } \\
\text { Value }\end{array}$ & $\begin{array}{l}\text { Simulated } \\
\text { Value }\end{array}$ & $\begin{array}{l}\text { Simulated } \\
\text { Value }\end{array}$ \\
\hline $\begin{array}{l}\text { Resonant } \\
\text { Frequency }\end{array}$ & $3.06 \mathrm{GHz}$ & $3.60 \mathrm{GHz}$ & $3.7 \mathrm{GHz}$ & $4.07 \mathrm{GHz}$ \\
\hline $\begin{array}{l}\text { Return Loss } \\
\text { (S11) }\end{array}$ & $-34.55 \mathrm{~dB}$ & $-36.00 \mathrm{~dB}$ & $-33.90 \mathrm{~dB}$ & $-11.30 \mathrm{~dB}$ \\
\hline VSWR & 1.22 & 1.122 & 1.325 & 1.40 \\
\hline Gain & $5.12 \mathrm{~dB}$ & $2.42 \mathrm{~dB}$ & $4.19 \mathrm{~dB}$ & $2.69 \mathrm{~dB}$ \\
\hline Directivity & $6.46 \mathrm{dBi}$ & $4.3 \mathrm{dBi}$ & $6.3 \mathrm{dBi}$ & $5.2 \mathrm{dBi}$ \\
\hline Bandwidth & $130 \mathrm{MHz}$ & $250 \mathrm{MHz}$ & & $110 \mathrm{MJz}$ \\
\hline
\end{tabular}

TABLE III. PERFoRMANCE CHARACTEISTICS OF CASE 3

\begin{tabular}{|l|l|l|l|l|}
\hline $\begin{array}{l}\text { Antenna } \\
\text { Parameter }\end{array}$ & $\begin{array}{l}\text { Simulated } \\
\text { Value }\end{array}$ & $\begin{array}{l}\text { Simulated } \\
\text { Value }\end{array}$ & $\begin{array}{l}\text { Simulated } \\
\text { Value }\end{array}$ & $\begin{array}{l}\text { Simulated } \\
\text { Value }\end{array}$ \\
\hline $\begin{array}{l}\text { Resonant } \\
\text { Frequency }\end{array}$ & $3.06 \mathrm{GHz}$ & $3.60 \mathrm{GHz}$ & $3.7 \mathrm{GHz}$ & $4.5 \mathrm{GHz}$ \\
\hline $\begin{array}{l}\text { Return Loss } \\
\text { (S11) }\end{array}$ & $-26.33 \mathrm{~dB}$ & $-27 \mathrm{~dB}$ & $-25.3 \mathrm{~dB}$ & $-13.88 \mathrm{~dB}$ \\
\hline VSWR & 1.12 & 1.22 & 1.25 & 1.30 \\
\hline Gain & $4.12 \mathrm{~dB}$ & $1.42 \mathrm{~dB}$ & $3.19 \mathrm{~dB}$ & $2.00 \mathrm{~dB}$ \\
\hline Directivity & $5.20 \mathrm{dBi}$ & $1.98 \mathrm{dBi}$ & $4.3 \mathrm{dBi}$ & $2.2 \mathrm{dBi}$ \\
\hline Bandwidth & $108 \mathrm{MHz}$ & $252 \mathrm{MHz}$ & & $108 \mathrm{MHz}$ \\
\hline
\end{tabular}

TABLE IV. SIZE REDUCTION OF PROPOSED PATCH

\begin{tabular}{|l|l|l|l|}
\hline S.No & Antenna $(\mathbf{G H z})$ & $\begin{array}{l}\text { Dimensions } \\
\mathbf{m m}^{2}\end{array}$ & Size Reduction \\
\hline 1 & 3.06 & 1131 & $72 \%$ \\
\hline 2 & 3.6 & 850 & $52 \%$ \\
\hline 3 & 3.7 & 780 & $47 \%$ \\
\hline
\end{tabular}

\section{CONCLUSION}

Patch Antennas play an important role in up to date communication technology. These minute elements can be designed at much ease as compared to other traditional antennas. They are frequency reconfigurable and easily adjustable elements. Patch Antennas offer a unique characteristics of multi band response when introduced with slots. However at every resonant frequency, their size varies and so the slots have no specific criteria either they should be placed on top or right or any other side. In this research a miniature antenna was presented with multi band response. Different techniques were considered in reducing the size of antenna and size reduction through slots was implemented. It was seen that with adding different slots on the large ground plane and radiating patch antenna exhibited Quad band response with resulting the size reduction of $72 \%$. Antenna with slots can offer low results as slots can effect antenna performing parameters through which antenna efficiency is affected. Their VSWR plots or impedance matching values are effected if slots are not planed and examined at each state and with higher VSWR values can horribly affect antenna performance. Superstrate configuration was implemented after reducing the size of antenna and a parasitic patch was placed at top of radiating patch. The parasitic patch was studied on different distance levels and at half wavelength distance antenna performance parameters showed satisfactory levels of performance. The reflection co efficient is main parameter of antenna and it showed enhanced results as compared to single radiating patch. These results can further be improved in future if this set up can be performed in a cavity box. By placing it in a cavity box we can improve its radiating patterns further and also can examine its gain and efficiency values., this technique has been previous proved helpful for narrow-band antennas. The technique can be validated by applying it to band notch version of the same antenna. Also this results can be checked for their behaviour response if the number of parasitic patches can be increased and their structure as it can lead to wider band response if the parasitic patch is used without addition of slots and can be used as a reflector. This set up was performed in a professional antenna simulator software Computer Simulation Technology 2014 and mesh size per wavelength was kept at 5 levels. The proposed antenna is miniaturized as compared to conventional antenna in size and has shown good bandwidth and gain alongside directivity and other performance parameters. The proposed antenna can be used in $\mathrm{S}$ band applications and Wi-Max and other small wireless technologies.

\section{ACKNOWLDEGMENT}

The authors would acknowledge the support and facilities provided by Iqra National University Peshawar, Pakistan

\section{REFERENCES}

[1] Chen, Zhi Ning, and Xianming Qing. "Dual-Band Circularly Polarized \$ S \$-Shaped Slotted Patch Antenna With a Small Frequency-Ratio." IEEE Transactions on Antennas and Propagation 58.6 (2010): 21122115.

[2] Saad Hassan Kiani, Khalid Mahmood and Ahsan Altaf, “A Linear Array for Short Range Radio Location and Application Systems" International Journal of Advanced Computer Science and Applications(IJACSA), 9(4), 2018. http://dx.doi.org/10.14569/IJACSA.2018.090420

[3] Christodoulou, Christos G., et al. "Reconfigurable antennas for wireless and space applications." Proceedings of the IEEE 100.7 (2012): 22502261.

[4] Saad Hassan Kiani, Khalid Mahmood, Ahsan Altaf and Alex J. Cole, "Mutual Coupling Reduction of MIMO Antenna for Satellite Services and Radio Altimeter Applications" International Journal of Advanced Computer Science and Applications(IJACSA), 9(4), 2018. http://dx.doi.org/10.14569/IJACSA.2018.090405

[5] Qian, Jian-Feng, et al. "A Wide Stopband Filtering Patch Antenna and Its Application in MIMO System." IEEE Transactions on Antennas and Propagation 67.1 (2019): 654-658.

[6] Zhu, Jianfeng, et al. "Wideband low-profile highly isolated MIMO antenna with artificial magnetic conductor." IEEE Antennas and Wireless Propagation Letters 17.3 (2018): 458-462.

[7] Wen, Dingliang, et al. "Design of a MIMO Antenna With High Isolation for Smartwatch Applications Using the Theory of Characteristic Modes." IEEE Transactions on Antennas and Propagation 67.3 (2019): 1437-1447.

[8] Zhang, C., Gao, J., Cao, X., Xu, L., \& Han, J. (2018). Low Scattering Microstrip Antenna Array Using Coding Artificial Magnetic Conductor Ground. IEEE Antennas and Wireless Propagation Letters, 17(5), 869872.

[9] Han, Z. J., Song, W., Zhu, Y. Q., \& Sheng, X. Q. (2018, December). RCS Reduction and Gain Enhancement for Patch Antenna by Using 
Low Profile EBG. In 2018 12th International Symposium on Antennas, Propagation and EM Theory (ISAPE) (pp. 1-2). IEEE.

[10] Jam, S., \& Simruni, M. (2018). Performance enhancement of a compact wideband patch antenna array using EBG structures. AEU-International Journal of Electronics and Communications, 89, 42-55.

[11] Islam, M. M., Islam, M. T., Samsuzzaman, M., \& Faruque, M. R. I. (2015). Compact metamaterial antenna for UWB applications. Electronics Letters, 51(16), 1222-1224.

[12] Abdalla, M. A., \& Ibrahim, A. A. (2013). Compact and closely spaced metamaterial MIMO antenna with high isolation for wireless applications. IEEE Antennas and Wireless Propagation Letters, 12, $1452-1455$.

[13] Huang, C. Y., \& Yu, E. Z. (2011). A slot-monopole antenna for dualband WLAN applications. IEEE Antennas and Wireless Propagation Letters, 10, 500-502.
[14] Qin, P. Y., Weily, A. R., Guo, Y. J., \& Liang, C. H. (2010). Polarization reconfigurable U-slot patch antenna. IEEE Transactions on Antennas and Propagation, 58(10), 3383-3388.

[15] Dang, L., Lei, Z. Y., Xie, Y. J., Ning, G. L., \& Fan, J. (2010). A compact microstrip slot triple-band antenna for WLAN/WiMAX applications. IEEE Antennas and Wireless Propagation Letters, 9, 11781181.

[16] Hu, W., Yin, Y. Z., Fei, P., \& Yang, X. (2011). Compact triband squareslot antenna with symmetrical L-strips for WLAN/WiMAX applications. IEEE Antennas and Wireless Propagation Letters, 10, 462-465.

[17] Cetiner, B. A., Crusats, G. R., Jofre, L., \& Biyikli, N. (2010). RF MEMS integrated frequency reconfigurable annular slot antenna. IEEE Transactions on Antennas and Propagation, 58(3), 626-632.

[18] Balanis, Constantine A. Antenna theory: analysis and design. John wiley \& sons, 2016. 